\title{
Peer-to-Peer Education of College Females on Sexual Health
}

\author{
Skelly, C. ", Hall, C., Risher, C., Brown, B. \\ Florida Southern College, Lakeland, 33809, Florida, United States
}

Copyright $\bigcirc 2018$ by authors, all rights reserved. Authors agree that this article remains permanently open access under the terms of the Creative Commons Attribution License 4.0 International License

\begin{abstract}
Objective: This study examined the sexual health knowledge of female undergraduate college students before and following a peer to peer, sexual health education intervention. Participants: Sixty-nine students participated in the study. Methods: Undergraduate female students from a central Florida private college completed paper-pencil questionnaires before and after a series of four peer-to-peer sexual health poster sessions. Results: Findings showed female undergraduate students had sexual health knowledge deficits prior to the intervention. Also, participant knowledge significantly increased pre- to post-test $(p<0.001)$. Conclusions: These results bring to light the continued sexual health knowledge deficits of undergraduate college students. Furthermore, the benefits of a peer-to-peer education programs on college campuses have the potential to increase undergraduate student's sexual health knowledge. Such programs may help students develop and maintain positive sexual health, including sexual self-efficacy, positive body image, and mutually respectful relationship development.
\end{abstract}

Keywords Sexual Health Knowledge, Peer to Peer Education, Sexual Health Education

\section{Introduction}

In 1964 the Sexuality Information and Education Council of the United States (SIECUS) was formed to address the need for adolescent and young adults to have access to accurate information about sex, sexuality and sexual health [1]. Sexually transmitted infections are the most prevalent of the infectious diseases in our country [2]. The National Prevention Strategy and Healthy People 2020 have emphasized the importance of reproductive sexual health through sexual health education [3-4]. Despite $90 \%$ of college age women noting formal sexual health education, many students continue to have significant knowledge gaps [5]. This is influenced by the fact that only 24 states mandate sexual health education in high schools [5]. Additionally, those states providing sexual health education do so inconsistently and often with inaccurate sexual health information [6].

Many states, including Florida, continue to endorse the Abstinence-Only-Until-Marriage programs despite the lack of evidence to support these programs [7]. Currently, many students enter college life with a lack of understanding and preparation to develop and maintain positive sexual health, including sexual self-efficacy, positive body image, and mutually respectful relationship development [7-8]. This is evident in the high incidence of sexually transmitted infections, intimate partner violence, and unintended pregnancies witnessed across United States College campuses [9-11]. Given the potential risk of exposure and knowledge deficit within the college population, interventions to increase sexual health knowledge in female college students is crucial to reducing sexually transmitted infection (STI) exposure and improving sexual health. Therefore, the present study examined the impact of a peer-to-peer educational intervention designed to provide female college student's sexual health information.

The effects of sexually transmitted infections can cause severe reproductive consequences and even death in some circumstances [12-13]. An estimated 16 billion dollars was spent treating these infections in 2015 alone [2]. Lifetime cost of treating incurable sexually transmitted infections is 15.6 billion dollars every year [14]. Sexually transmitted infections continue to climb in the United States [15].

Additionally, female college students may encounter intimate partner violence (IPV). IPV includes any combination of physical, psychological, and sexual abuse towards a romantic partner [16]. Nearly twenty percent of college females report having experienced sexual assault [17]. There are multiple risk factors associated with sexual violence and IPV on college campuses including alcohol consumption, attendance to college parties and co-ed dormitories [18-19].

Access to campus resources is shown to reduce post sexual assault emotional and psychological consequences 
[20]. Primary prevention programs may provide students with the necessary skills and resources to minimize their risk for sexual violence [11].

Forty five percent of the pregnancies in 2011 were unintended [21]. Alarmingly, over half of the reported unintended pregnancies in the United States are occurring in the college aged population and many do not fully understand or have misconceptions regarding emergency contraception options. [22]. Despite current declines in unintended pregnancies, the 14-24-year-old age range continues to be a high-risk population [14]. Continued efforts to address this issue nationally through legislation and campaigns prevail, but there is much more work to be done because racial, economic and geographic disparities persist. [23].

\section{Objectives}

To identify an effective method to promote sexuality information and education within the college female population, a team of nurse faculty collaborated to develop a peer-to-peer education intervention program. Peer to peer education has been effective in promoting healthy behaviors among college students [24].

The purpose of this study was to examine the sexual health knowledge of female undergraduate college students before and following a sexual health education intervention, "What's Up Down There." Senior community health nursing students were trained to deliver content in four areas: 1) female anatomy and sexual health 2) sexually transmitted infections 3) contraception 4) safety/sexual respect and awareness. A second purpose was to examine current sexual health knowledge and practices among the female undergraduate college students to better understand future sexual health educational needs.

\section{Materials and Methods}

University Institutional Review Board approval was obtained prior to the start of the study. A minimum of 54 participants were needed to ensure power of the anticipated t-test. All female undergraduate students at a central Florida private college were invited to participate in the "What's Up Down There" event. Flyers were posted throughout campus for recruitment of participants. Additionally, the event was listed on the campus "Passport" system, which is a campus wide program designed to expose students to experiences outside of the classroom. Students attending the event were invited to participate in the study. Those who agreed to participate completed a written consent document. A raffle drawing of a single $\$ 100.00$ gift card was used as remuneration for the students who participated in the study.

\subsection{Tool}

A demographic form and researcher developed questionnaire, the Sexual Health Knowledge Questionnaire (SHKQ), were administered after the consent was obtained and prior to participation in the event. The event included four 15 -minute poster sessions where trained senior community health nursing students provided oral presentations, distributed materials, and answered participant questions. Participants were given a card to be stamped at each individual station indicating completion of that station. Once all four stations had been visited, participants completed the SHKQ posttest and their completed card was entered in the raffle. The time to complete all event activities, including the four stations and the pre-test and the post-test, was 75 minutes.

Using SPSS version 22 sample characteristics were analyzed, and variable distribution was evaluated. Given the relative normal distribution of the data, paired t-tests were performed to determine differences between pre-test and post-test SHKQ scores. Probability values less than 0.05 were considered significant.

Table 1. Event Overview

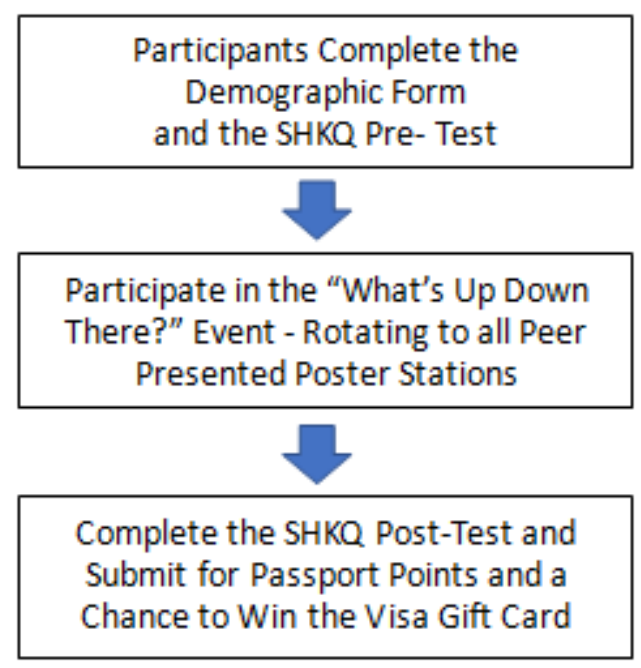

\subsection{Analysis}

Data analysis included descriptive statistics of demographic data and paired t-tests of the SHKQ. Descriptive statistics included: 1) previous sexual health education 2) student resources 3) number of sexual partners 4) type(s) of sexual activity 5) history of sexually transmitted infections 6) types of birth control used.

\section{Results}

The final sample size of students who participated in the study was sixty-nine with sixty-seven fully completed questionnaires $(\mathrm{N}=67)$. The majority $(74.6 \%)$ of participants indicated they received sexual health 
education in high school, however most indicated that the amount of sexual education received was not adequate (68.7\%).

About half $(53.7 \%)$ of the participants denied sexual activity. Most participants who were sexually active noted a history of activity with one to three partners $(62.8 \%)$. Seventeen percent had been sexually active with more than six partners. Of those who were sexually active 13 (19.4\%) engaged in anal sex. The remaining participants reported engaging in a variety of oral and vaginal sexual activity. Only two of the participants indicated a history of sexually transmitted infection(s): one participant indicated a history of chlamydia and another participant indicated a history of herpes simplex. Of the participants who were sexually active most used condoms, oral birth control, or a combination of other methods as their primary means (93.75\%). Two of the sexually active participants did not use any form of birth control. The remaining two indicated other methods as their form of birth control.

Table 2. Paired Sample Correlations of Pre/ Post QSHK

\begin{tabular}{|c|c|c|c|}
\hline \multicolumn{4}{|c|}{ t-test } \\
\hline $95 \%$ Confi & $\begin{array}{l}\text { oper Le } \\
\text { ope }\end{array}$ & t $\quad d f$ & Sig.(2-tailed) \\
\hline $\begin{array}{l}\text { Pair 1: Total Score } \\
\text { QSHKa - } \\
\text { Total Score } \\
\text { QSHKb }\end{array}$ & -2.022 & $7.051 \quad 66$ & .000 \\
\hline
\end{tabular}

SHKQ scores ranged from 12-37 for the pre-test and 19-37 for the post-test. Examination of paired t-Tests for total score on the SHKQ revealed a significant increase in participant knowledge following the intervention. The mean score on the SHKQ prior to the intervention was $29.75(\mathrm{SD}=4.11)$ and following the intervention the mean score increased to $32.57(\mathrm{SD}=3.22)(\mathrm{p}<0.001)$ (see table 1).

\subsection{Discussion}

As nursing professors, watching senior students engage in a peer to peer educational event was very exciting. Students attending the "What's Up Down There" event were observed actively listening and asking questions. Senior students explained the topics as they pointed to the poster that they created. The results showed that the students who attended the event had significantly higher knowledge upon exiting. The demographics revealed that almost half of the students were sexually active. Alarmingly, some students did report unprotected sexual activity, validating the need for this sexual health education. Through educational interventions such as this, students may have a better understanding of their sexual health, contraception options, sexually transmitted infections, and have improved safety awareness. Knowledge gained by students who participated in this event may prevent an unintended pregnancy, sexually transmitted infection, or even a violent occurrence.

\subsection{Limitations}

While the present study demonstrated a significant increase in knowledge following the peer-to-peer intervention, knowledge retention over time was not assessed. Future studies should include assessment of knowledge retention over time. A second limitation includes the study design. The research team used a non-probability sample which reduces the generalizability of the findings. The sample size was adequate, although small. A larger sample would improve generalizability. Another limitation is that the tool has not been validated as it was researcher developed for this study. The tool was also a true/false design and results were collected immediately after the event. Lastly, the sample included only female undergraduate students, future studies are needed to examine the benefits of peer-to-peer education interventions on sexual health knowledge among male undergraduate students.

\section{Conclusions}

The findings of this study are consistent with previous research that identified sexual health knowledge deficits $[8,9,16]$. Sexuality is a unique biologic and social matter. The education on sexual health for this age group is important so that students can better interpret and understand their own sexual health. Looking toward the future needs of the college female population, peer to peer education is a viable option in the college setting. Topics which address the knowledge needs of the student can be effectively taught using this approach and contribute to the health of the peer audience.

\section{Conflict of Interest Disclosure}

The authors have no conflict of interest to report.

\section{Funding}

This study received no external funding.

\section{REFERENCES}

[1] Sexuality Information and Education Council of the United 
States. Online available from www.siecus.org/index.cfm?f useaction $=$ Page. viewPage \&pageId $=493 \&$ parentID $=472$, 2011.

[2] Mark, H., Dhir, A. \& Roth, C. Sexually transmitted infections in the United States: Overview and update. America Journal of Nursing, Vol. 115, No. 9, 34-44, 2015.

[3] National Prevention Council, National Prevention Strategy, Washington, DC: US Department of Health and Human Services, Office of the Surgeon General. doi:10.1037/e540482013, 2011.

[4] Department of Health and Human Services (US). Healthy People 2020: Leading health indicators. Online available from http://www.healthypeople.gov/2020/LHI/default.aspx. , 2014.

[5] Toews, M., \& Yazedjian A. College students' knowledge, attitudes, and behaviors regarding sex and contraceptives. Journal of Family \& Consumer Sciences. Vol. 104, No. 3, 16-23, 2012.

[6] Formal sex education increasingly omits topics important to adolescents' reproductive health. Perspectives on Sexual and Reproductive Health. Vol. 48, No. 3, 153-154, doi:10.1363/48e10616, 2016.

[7] Santelli, J., \& Ott, M. A., Lyon, M., Rogers, J., Summers, D., \& Schleifer, R. Abstinence and abstinence-only education: A review of US policies and programs. Journal of Adolescent Health. Vol. 33, No. 1, 72-81, 2006.

[8] Schalet, A. Beyond abstinence and risk: A new paradigm for adolescent sexual health. Women's Health Issues. Vol. 21., No. 3 Suppl., S5-S7, 2011.

[9] Moore E., \& Smith W. What college students do not know: Where are the gaps in sexual health knowledge? Journal of American College Health. Vol. 60, No. 6, 436-442, 2012.

[10] Centers for Disease Control and Prevention (CDC). Sexually transmitted disease surveillance. US Department of Health and Human Services. Online available from https://www.cdc.gov/std/stats15/std-surveillance-2015-prin t.pdf. 2015.

[11] Krebs C., Lindquist C., Warner T., Fisher B., \& Martin S. College women's experiences with physically forced, alcohol- or other drug-enabled, and drug-facilitated sexual assault before and since entering college. Journal of American College Health. Vol. 57, No. 6, 639-647, 2009.

[12] Finer L. \& Zolna M. Shifts in intended and unintended pregnancies in the United States, 2001-2008. American Journal of Public Health. Vol. 104, No. S1, S43-S48, 2014.

[13] Centers for Disease Control and Prevention (CDC). CDC fact sheet. Reported STDs in the United States: 2014 national data for chlamydia, gonorrhea, and syphilis. Online available from https://stacks.cdc.gov/view/cdc/36834, 2014.
[14] Centers for Disease Control and Prevention (CDC). CDC Fact Sheet: Incidence, prevalence, and cost of sexually transmitted infections in the United States. Online available from

https://www.cdc.gov/nchhstp/newsroom/docs/factsheets/S TI-Incidence-Prevalence-Cost-Fact-Sheet-508.pdf, 2013.

[15] Centers for Disease Control and Prevention (CDC) Sexually Transmitted Disease Surveillance, 2015. United States Department of Health and Human Services; Online available from https://www.cdc.gov/std/stats15/std-surveillance-2015-prin t.pdf, 2016.

[16] Sutherland, M.A., Fantasia, H.C., \& Hutchinson, M. K. Screening for intimate partner sexual violence in college women: Missed opportunities. Women's Health issues. Vol. 26, No. 2, 217-224, 2016.

[17] Exner D. \& Cummings N. Implications for sexual assault prevention: College students as prosocial bystanders. Journal of American College Health. Vol. 59, No. 7 , 655-657. doi: 10.1080/07448481.2010.515633, 2011.

[18] Pedrelli P., Bitran S., Shyu, I., Baer, L., Guidi, J., Tucker, D., Vitali, M., Fava, M., Zisook, S., \& Farabaugh, A. Compulsive alcohol use and other high - risk behaviors among college students. American Journal of Addictions. Vol. 20, No. 1, 14-20. doi: 10.1111/j.1521-0391.2010.00090.x, 2011.

[19] Bersamin M., Paschall M., Saltz, R., \& Zamboanga B. Young adults and casual sex: The relevance of college drinking settings. Journal of Sex Research. Vol. 49, No. 2/3, 74-281. doi:10.1080/00224499.2010.548012, 2012

[20] Suzuki, Y.E., \& Bonner, H.S. Factors associated with college students' responses to rape disclosure scenarios: Influence of gender, rape, characteristics, and opinions about health professionals. Journal of School Violence. Vol. 16, No. 2, 160-172, 2017.

[21] Hickey, M.T. Female college students' knowledge, perceptions, and use of emergency contraception. JOGNN. Vol. 38, 399-405, 2009.

[22] Finer, L., \& Zolna, M. Declines in unintended pregnancy in the United States, 2008-2011. The New England Journal of Medicine. Vol. 374, No. 9, 843-852. doi: 10.1056/NEJMsa1506575, 2016.

[23] Jozkowski, K.N. \& Crawford, B.L. The status of reproductive and sexual health in southern USA: Policy recommendations for improving health outcomes, Sex Res Social Policy. Vol. 13, 252-262. Online available from https://ezproxy.flsouthern.edu:2432/10.1007/s13178-015-0 208-7, 2016.

[24] Bulduk S. \& Erdogan S. The effects of peer education on reduction of the HIV/sexually transmitted infection risk behaviors among Turkish university students. Journal of the Association of Nurses in AIDS Care. Vol. 23, No. 3, 233-243, 2012. 